\title{
A REVIEW OF THE APPLICABILITY OF GAMIFICATION AND GAME-BASED LEARNING TO IMPROVE HOUSEHOLD-LEVEL WASTE MANAGEMENT PRACTICES AMONG SCHOOLCHILDREN
}

\author{
Malida Magista ${ }^{1}$, Bella Lexmita Dorra ${ }^{1}$, Thye Yoke Pean ${ }^{2 *}$ \\ ${ }^{1}$ Programs Team, WISE-WASH in Southeast Asia, Komp. OPI Jl. Bali IV AX No. 21, 15 Ulu, \\ Seberang Ulu 1, Kota Palembang, Sumatera Selatan 30257, Indonesia \\ ${ }^{2}$ Core Team, WISE-WASH in Southeast Asia, 96 Jalan Leban 577628, Singapore
}

(Received: June 2018 / Revised: August 2018 / Accepted: December 2018)

\begin{abstract}
Knowledge strongly affects attitudes toward waste management; thus, embedding an environmental mentality at a young age is crucial. Game-based interventions, such as gamification and game-based learning, have huge potential to be effective learning tools. This paper examines the potential of gamification to improve waste management practices among schoolchildren through a narrative review of 25 papers on gamification for waste management and gamification for schoolchildren. The effectiveness of game-based learning and gamification in mitigating waste management issues with schoolchildren has not yet been well-described in the literature; however, the evolving market in related sectors is a strong indication of their potential. A robust understanding of social and behavioral theories is necessary for implementing gamification and game-based learning effectively. Additionally, the game elements, design, and mechanics that can achieve the most positive impacts should be explored further. It is hoped that this study will contribute to the body of knowledge in the environmental sector on gamification as an innovative process for improving household-level waste management behavior among schoolchildren.
\end{abstract}

Keywords: Gamification; Game-based learning; Recycling; Schoolchildren; Waste management

\section{INTRODUCTION}

\subsection{Municipal Solid Waste}

Waste is generated from household, industrial, and commercial activities. Municipal solid waste (MSW) refers to everyday items that people use and then throw away. Globally generated MSW is predicted to rise to 2.2 billion tons by 2025 , with the generation rate increasing faster than the urbanization rate. MSW is not well-managed, especially in low- and middle-income countries (Hoornweg \& Bhada-Tata, 2012; World Bank, 2018).

Waste in households can be managed through the 3Rs: reducing waste (e.g. purchasing items with less packaging), reusing items (e.g. reusing old clothing as rags), and recycling (e.g. paper; NEA, 2018). These practices can be improved. A report from the European Environmental Bureau \& Eunomia (2017) found that household recycling rates in the top ten countries ranged from $45.8 \%$ to $57.0 \%$. In Indonesia, the national recycling rate is $2 \%$ (Sekito et al., 2013).

Individuals' awareness of and behaviors towards waste management practices play important

*Corresponding author's email: yokepean@washinseasia.org, Tel. +65-93361276

Permalink/DOI: https://doi.org/10.14716/ijtech.v9i7.2644 
roles in improving household waste management. Knowledge strongly affects attitudes towards waste management (Dung et al., 2017). Embedding an environmental mentality from a young age is crucial, as is enabling proper awareness in school settings (Licy et al., 2013). For example, school programs in Singapore include workshops on environmental issues and advocacy skills; networks of teachers who plan, coordinate, and implement environment programs; and trainings for cub scouts and brownies on topics like the 3Rs (Clean \& Green Singapore, 2018).

\subsection{Game-based Learning and Gamification}

Game-based interventions can be effective for learning. Computer and video games are significant in the entertainment industry, having experienced rapid growth and success over the past few decades. The gaming market has 2.2 billion consumers across a wide range of ages (ESA, 2017). In 2017, gaming revenue in the United States (US) was three times higher than that of the movie industry (Nath, 2016; ESA, 2018). In fact, 65\% of households in the US have at least one family member who plays games at least three hours a week (Newzoo, 2017). It is unsurprising, then, that Prensky (2003) believed that motivation for learning could be rekindled by inserting educational content into a game. Indeed, Katsaliaki and Mustafee (2015) stated that games are a great alternative for teaching, training, and entertainment (edutainment or educational entertainment), leading to positive learning outcomes.

\subsubsection{Game-based learning}

Game-based learning (GBL) delivers information and knowledge through the medium of play. A game-based approach is expected to improve user engagement with designed information and knowledge (Felicia, 2014). GBL products have been demonstrated in numerous subjects, such as business, engineering, economy, and politics (Pivec et al., 2003). GBL approaches have also been widely used environmental education. Juan and Chao (2015) implemented a green building strategy game for architecture major students, while Ye et al. (2007) designed an educational game to improve awareness of water, waste, and land problems.

\subsubsection{Gamification}

Besides GBL, game-inspired approaches like gamification have also gained attention. Gamification is known for its ability to educate people in all kinds of sectors. As an emerging concept, gamification still lacks a clear definition (Kapp et al., 2013; Matallaoui et al., 2017). It has been described as the utilization of game design elements for non-game settings (Deterding et al., 2011), involving the insertion of game features like users, challenges, scores, levels, badges, and rankings (Kiryakova et al., 2014) into a game to achieve a certain goal (Duggan \& Shoup, 2013). The popularity of gamification has been demonstrated in many sectors, such as commerce, the environment, education, and medicine. It has been successful in increasing people's engagement and the success of an intervention (Licy et al., 2013).

Gamification was first developed in 2002 for the gaming industry through Xbox Live, an online game and media delivery service (Webley \& Cham, 2016). This success was followed by the use of gamification to address social and environmental challenges, for example, by helping schoolchildren become more active and motivated in learning (Kiryakova et al., 2014).

\subsubsection{Game-based learning versus gamification}

GBL and gamification share similarities, yet they have distinct concepts and purposes. GBL utilizes actual games to deliver knowledge and skills, such that people learn while engaging in a game activity. On the other hand, gamification merely applies game elements to the design of activities or interventions. In gamification, people participate in an activity embedded with game elements, such as receiving badges for completing a task (Kapp et al., 2013). 


\subsection{Objective}

The effectiveness of GBL and gamification has been demonstrated in numerous sectors (Pivec et al., 2003). However, few studies have considered household waste management. This paper aims to fill this gap by examining the potential of gamification to improve waste management practices among schoolchildren through a review of gamification in related settings: gamification to promote waste management and gamification for schoolchildren.

\section{METHODS}

A narrative literature review was conducted between May and June 2018 (Figure 1).

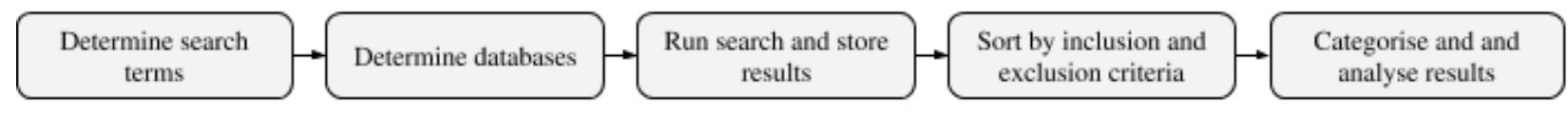

Figure 1 Steps in the review process

\subsection{Search Strategy}

A search of the literature published in any year was performed using the databases ScienceDirect, EBSCO, Scopus, and Web of Science. The search strategy used combinations of the following terms: 'gamification,' 'game-based learning,' 'waste management,' 'recycling,' and 'schoolchildren.' Reference lists of selected publications were examined to identify additional relevant literature. The search was limited to the English language.

\subsection{Inclusion and Exclusion Criteria}

A set of inclusion and exclusion criteria was applied to identify relevant articles for the review. Studies were included if they addressed gamification or GBL matching the variables of interest: applications in waste management or environmentally-friendly behaviors or applications targeting schoolchildren. For this paper, environmentally-friendly behavior was defined as comprising actions that reduce harm to the environment, such as saving energy, conserving water, and so on. Schoolchildren referred to children in pre-elementary, elementary, and high school education. The articles were also required to meet the following criteria: (1) empirical, review, or conceptual studies, book or book chapters, opinion articles, theses and dissertations, or letters to the editor; (2) qualitative or quantitative studies; and (3) published in any year. Studies were excluded if they: (a) did not examine the use of gamification (particularly, articles focusing solely on serious games) or GBL; or (b) did not consider environmentally-friendly behaviors or did not describe schoolchildren as their target population.

\section{RESULTS AND DISCUSSION}

\subsection{Results}

Results should be clear and concise. Results should be clear and concise Results should be clear A comprehensive article search of four journal databases with the search queries yielded a total of 138 titles. Upon examination of the language, titles, abstracts, and full texts, 25 articles were included in the review (Table 1). These articles focused on either gamification or GBL behaviors towards waste management or among children.

\subsubsection{Gamification to promote waste management and related behavior}

Waste management practices fall under sustainable development, sustainable lifestyle choices, environmentally-friendly behavior, and ecologically friendly behavior. The search identified 12 articles that addressed gamification or GBL to promote waste management, either as part of a family of behavior related to sustainable development or as a specific behavior on its own. 
Table 1 Overview of studied articles

\begin{tabular}{|c|c|c|c|c|}
\hline Paper & $\begin{array}{c}\text { Type of } \\
\text { study/article }\end{array}$ & $\begin{array}{c}\text { Target } \\
\text { behavior/issue }\end{array}$ & $\begin{array}{l}\text { Target/study } \\
\text { population }\end{array}$ & Type of intervention \\
\hline Berengueres et al. (2013) & Experimental & Recycling & College campus & Gamification \\
\hline Comber \& Thiem (2017) & Experimental & $\begin{array}{l}\text { Recycling and food } \\
\text { waste }\end{array}$ & Student households & Gamification \\
\hline Comber et al. (2013) & Experimental & $\begin{array}{l}\text { Recycling and food } \\
\text { waste }\end{array}$ & Young adults & Gamification \\
\hline Diah et al. (2012) & Functionality test & Recycling & Primary school & Game-based learning \\
\hline Dicheva et al. (2015) & Systematic mapping & Education & N/A & Gamification \\
\hline Eder (2016) & Descriptive & Waste segregation & 4-5 years old & Gamification \\
\hline Fadhil \& Villafiorita (2017) & Prototype testing & $\begin{array}{l}\text { Health diets; food } \\
\text { waste }\end{array}$ & Primary school & Gamification \\
\hline González et al. (2016) & Experimental & Healthy lifestyle & $8-12$ years old & Gamification \\
\hline González-Briones et al. (2018) & Experimental & Waste management & Public & Gamification \\
\hline Hirose et al. (2004) & Experimental & Waste management & Undergraduate & Game-based learning \\
\hline Jones et al. (2014) & Experimental & Diets & Elementary school & Gamification \\
\hline Kasurinen \& Knutas (2018) & Systematic mapping & General & N/A & Gamification \\
\hline Kayımbaşığlu et al. (2016) & Experimental & $\begin{array}{l}\text { Second language } \\
\text { learning }\end{array}$ & Pre-school & Gamification \\
\hline Kostenius et al. (2018) & Consultative & Health education & Primary school & Gamification \\
\hline Morganti et al. (2017) & Systematic review & Energy efficiency & N/A & $\begin{array}{l}\text { Serious games and } \\
\text { gamification }\end{array}$ \\
\hline Mostowfi et al. (2015) & Evaluation & $\begin{array}{l}\text { Recycling; waste } \\
\text { separation }\end{array}$ & $>9$ years old & Game-based learning \\
\hline Katsaliaki \& Mustafee (2015) & $\begin{array}{l}\text { Methodological } \\
\text { review }\end{array}$ & $\begin{array}{l}\text { Sustainable } \\
\text { development }\end{array}$ & N/A & Game-based learning \\
\hline Katsaliaki \& Mustafee (2012) & Literature review & $\begin{array}{l}\text { Sustainable } \\
\text { development }\end{array}$ & N/A & Serious games \\
\hline Lynch (2018) & Descriptive & Plastic pollution & Public & Gamification \\
\hline Recyclebank (2012) & Descriptive & Recycling & Public & Gamification \\
\hline Rutberg \& Lindqvist (2018) & Experimental & $\begin{array}{l}\text { Active school } \\
\text { transportation }\end{array}$ & Elementary & Gamification \\
\hline Seaborn \& Fels (2015) & Systematic survey & General & N/A & Gamification \\
\hline Soboleva et al. (2018) & Literature review & Education & Students & Gamification \\
\hline Wu \& Huang (2015) & Experimental & $\begin{array}{l}\text { Urban waste } \\
\text { management }\end{array}$ & $\begin{array}{c}\text { Undergraduate and } \\
\text { elementary }\end{array}$ & Game-based learning \\
\hline Yang et al. (2015) & Experimental & English learning & Elementary & Game-based learning \\
\hline
\end{tabular}

Kasurinen and Knutas (2018) found that 25 (8.1\%) of 308 proof-of-concept papers described 'some functional prototype or more sophisticated gamified services' designed to steer people towards more ecologically friendly or sustainable lifestyle choices, including recycling. They considered this to be one of the trendiest areas in gamification research. Indeed, Katsaliaki and Mustafee (2015) noted that a number of serious games were being developed to tackle the issues of sustainable development. One game described was SOS21, in which citizens and administrators were part of an online community to tackle global and local sustainable issues, such as finding places where particular waste must be collected (Katsaliaki \& Mustafee, 2012).

Other authors focus on applications to improve waste management practices. The only widely implemented example found is Recyclebank (2002) in the US. Launched in 2004, Recyclebank rewards people who recycle with. On Recyclebank's website, customers can earn more points by playing games, recycling specific items, and more. Customers can redeem their points for products or discounts or donate to environmental education programs. Unfortunately, the article did not describe the initiative's outputs or outcomes. Another example of point use, OpenLitterMap, enables any smartphone user to obtain cryptocurrency by producing open geospatial data on litter. Points are rewarded for uploading successfully verified images and being the first to upload from a certain location. At the point of writing the paper, approximately 8,200 photos and 28,000 examples of litter from over 150 contributors had been verified (Lynch, 2018). On a significantly smaller scale, Berengueres et al. (2013) designed a 
recycle bin to release a Nintendo ${ }^{\mathrm{TM}}$ coin sound and change the screen from a poker face to a happy emoticon for one second when a user dropped in a PET bottle. Tested over three weeks, the authors found that this simple intervention increased recycling rates by a factor of three. However, it should be noted that Seaborn and Fels (2015) did not consider this to be an example of gamification, but, rather, successful affective interface design.

Gamification has also been used in mobile applications. BinCam is a trash bin that employs multiple forms of engagement and feedback, such as instantly uploading a picture of trash to a person's Facebook account. Deployed in six student houses at Newcastle University, the bin raised awareness of recycling and food waste behavior, with some gamification elements working better than others (Comber et al., 2013; Comber \& Thieme, 2017). Moving away from municipal waste, the Industrial Waste Game aimed to enable players to understand the social dilemma between individual interests of hazardous dumping and the social cost of treating pollution. A survey of 213 undergraduate students who played this game found increased awareness and understanding of industrial waste problems (Hirose et al., 2004). Government involvement was demonstrated in GarbMAS, a gamification approach to increase people's participation in recycling through a garbage tax reduction. This intervention was expected to address municipal waste problems polluting the air, land, and water, and it increased residents' participation by $34.2 \%$ and total waste collection by $29.4 \%$ (González-Briones et al., 2018).

These examples positively indicate the effectiveness of gamification for promoting aspects of waste management in different ways. On the other hand, Morganti et al.'s (2017) overview of the effects of serious games and gamification for engaging in pro-environmental behaviors for energy efficiency suggests conflicting short- and long-term effects of such games.

\subsubsection{Use of gamification with schoolchildren}

As games have become more popular due to their potential for use in school, studies have noted the promising application of gamification or digital GBL to education. Gamification for schoolchildren has been applied in various contexts, ranging from enhancing learning to promoting healthy behaviors. The search found eight articles addressing gamification for schoolchildren. Of these, four discussed the application of gamification in the learning process, while the remainder explored the use of gamification for promoting healthy behaviors and health education in schoolchildren.

Kayımbaşığlu et al. (2016) found significant improvement in language acquisition, reduction in distractions, and escalation of the learning curve when using gamification-based teaching. Teachers/language instructors could assign different levels of assessments based on pedagogic level and behaviors, such as in an assignment in which students were given points for matching one figure to another. In another application, Soboleva et al. (2018) investigated the didactic potential of gamification for teaching modelling. The authors concluded that use of the gamification platforms and services increased motivation and visual expression in learning a subject with abstract theoretical concepts, while also improving the efficiency of the learning process. Their gamification approach encouraged students to be more active in their cognitive processes and helped consolidate knowledge and deepen and broaden understanding of the information objective. However, these benefits could only be achieved when the gamification was designed based on the schoolchildren's need.

Well-designed and appropriate use of gamification is also important. Dicheva et al. (2015) found that not all game mechanisms and dynamics should be used in an educational context. They observed that badges and leaderboards had a more positive influence on students than points, avatars, levels, and virtual goods. Similarly, Yang et al. (2016) found that digital badges and leaderboard rankings were crucial to enhancing the self-efficacy and learning performance of students studying English. They also suggested that a friendly, effective, enjoyable, and 
interesting game interface may help create a positive attitude that could enhance students' selfefficacy. Dicheva et al. (2015) noted that applying gamification in learning requires a technological infrastructure and a proper instructional framework that supports the incorporation and visualization of selected game mechanisms and dynamics. Not all institutions are able or ready to provide such infrastructure, nor have the human resources to design, adapt, and/or maintain the required infrastructure.

Although Dicheva et al. (2015) believed that computer science/IT subjects are more suitable to the application of gamification for schoolchildren, several studies have begun to examine the use gamification in health. Rutberg and Lindqvist (2018) used such elements as badges and levelling challenges in an Active School Transportation program. Students were divided into walking and cycling groups, and teachers designed complementary four-week assignments linked to the curriculum, such as counting the number of people the students' met on the way to school and observing signs of spring. The program not only increased students' motivation and efforts to succeed in the challenges, but also promoted learning and healthy behaviors. Another study used a participatory approach to encourage 18 students aged 10 to 12 years old to develop ideas promoting physical activity. In one idea, different levels of movement were set as goals. The recorded data were compiled to visualize progress, achievements, and goals (Kostenius et al., 2018).

Gamification has also been used to improve diets. In one study by Jones et al. (2014), 180 elementary school students were given a goal to be above the 60th percentile of the range of consumption over 10 days of consuming daily targeted fruits or vegetables, which encouraged the students to eat more fruits and vegetables during lunch without setting a specific amount. This initiative resulted in a significant increase in the consumption of fruit and vegetables. Intake was still below that recommended by the US Department of Agriculture, although the authors argued that this gap might have narrowed if the intervention had been conducted over a longer period. While this study had limitations, such as a limited sample size, the result suggests strong feasibility and efficacy of gamification with schoolchildren.

\subsubsection{Gamification for waste management with schoolchildren}

There are several examples of the application of gamification to promote waste management among schoolchildren. Unfortunately, none of these studies have evaluated their games' ability to improve waste management knowledge, attitudes, or practices to any significant degree.

Eder (2016) designed an Android game application to teach how to segregate waste. A game map shows different places the player can visit, such as the house or the school. At each place, the player picks up trash on the floor and puts it into biodegradable or non-biodegradable bins for points. The game was tested with four- to five-year-old pupils. The children were active and motivated to learn the difference between biodegradable and non-biodegradable waste, but needed assistance from parents and teachers to achieve for better learning, especially in terms of knowledge about waste classification. Jom Kitar Semula (JOKS) helps primary school children learn to recycle their daily waste. Used at home or in schools, it prompts players to collect recyclable items while avoiding obstacles. After collecting all the items, players recycle the items in the correct bins. Players must complete three levels (village, theme park, and city) to finish the game. Unfortunately, the completed game has only been tested for functionality (Diah et al., 2012). CiboPoliBot was initially created to increase schoolchildren's knowledge of diet and food waste management and reduction and was subsequently integrated with a chatbot system. The game consists of a series of steps in which players make choices and acquire points depending on their food choices and wastage. It also includes quizzes that award points. Beyond the game elements, the chatbot aims to make the learning process more engaging. Infield testing of the initial prototype was carried out with 44 schoolchildren, but the game has not yet been deployed (Fadhil \& Villafiorita, 2017). 
To a lesser extent, game-based approaches have also been applied offline. Mostowfi et al. (2016) used the Fun Toolkit to design a board game on recycling for twenty 7- to 12-year-old children. Played by four individuals, the game is won by the first player to complete the puzzle. The authors asserted that an educational board game can increase knowledge and self-efficacy outcomes through perceived fun, encouraging individuals to initiate or sustain without teachers or others present to manage the game.

The final game examined ties waste management to city development, teaching players about the costs associated with waste processing and the values of fairness and reciprocity. Players act as city administrators, allocating resources to economic development or environmental protection. If players focus too much on economic development, a natural disaster occurs. If they focus too much on environmental protection, the city's economic development falters. The game was tested with adolescents and young adults, but the study did not consider whether the game affected knowledge, attitudes, or practices (Wu \& Huang, 2015).

\subsection{Discussion}

The emerging popularity of GBL and gamification in waste management is not well represented in the literature, which focuses more on education (Liu et al., 2011; Dicheva et al., 2015). This does not necessarily reflect a lack of potential for GBL and gamification to address waste management issues. We postulate that the lack of information specific to waste management is due to the limited academic interest. Personal observations and internet searches reveal a myriad of practical applications that focus on waste management, such as Recyclebank (2012), Ecofunopoly (2018), and Eco (2018).

The articles written about the effectiveness of GBL and gamification in promoting waste management focused primarily on short-term outcomes. In a usability trial, pre-school teachers perceived iTrash as an applicable learning platform (Eder, 2016). Wu and Huang (2015) observed players' attitudes while playing a solid waste management simulation game. Similar assessments were conducted by Comber et al. (2013), who examined BinCam using surveys, and Berengueres et al. (2013), who measured collection rates in an emoticon recycle bin.

The application of gamification or GBL in education has also been expanded to waste management for schoolchildren (Diah et al., 2012; Eder, 2016; Mostowfi et al., 2016; Fadhil \& Villafiorita, 2017). Interestingly, all the reviewed studies produced positive outcomes concerning waste management knowledge, attitudes, and practices. These positive outcomes were attributed to the adoption of game elements like badge and leveling mechanisms. Scores, levels, and leaderboards encouraged children to progress and seek feedback according to the schedule set by their instructors/teachers (González-Briones et al., 2018).

However, some authors noted the need to consider enabling factors (Dicheva et al., 2015). Integrating gamification or GBL requires a multicomponent approach that could be expensive in terms of labor and equipment/infrastructure, with uncertain outcomes. Stickers, videos, and tangible rewards are needed. Instructors/teachers are required to deliver challenges, record points, and distribute rewards (Jones et al., 2014). Simply applying gamification mechanisms without an instructional framework will not significantly impact user activity (Hamari, 2013; Dicheva et al., 2015). Finally, effective game design requires comprehensive understanding and knowledge of social learning theory, behavioral analysis, and gamification principles (Jones et al., 2014).

While the findings show promise for gamification or GBL to improve waste management practices among schoolchildren, questions remain. First, to what extent are gamification or GBL interventions effective in improving schoolchildren's knowledge, attitudes, and practices? Second, can affordable materials and labor facilitate adoption in schools? Further studies considering these factors should be undertaken. 


\section{CONCLUSION}

The effectiveness of GBL and gamification in addressing waste management issues among schoolchildren has not been well described in the literature. Observed benefits are limited to short-term outcomes and usability evaluations, neglecting long-term impacts on awareness and behavior. However, the evolving market in GBL and gamification in related applications is a strong indication of their potential as an approach to promote household waste management practices, such as reducing waste produced, reusing items for similar or new purposes, and recycling.

Implementing effective GBL and gamification that is appropriate for schoolchildren and for addressing waste management issues demands a robust understanding of social and behavioral theories. Additionally, the game elements, designs, and mechanics that can achieve the most positive impacts should be explored further. It is hoped that this study will contribute to the body of knowledge in the environmental sector on gamification as an innovative process for improving household-level waste management behaviors among schoolchildren.

\section{REFERENCES}

Berengueres, J., Alsuwairi, F., Zaki, N., Ng, T., 2013. Gamification of a Recycle Bin with Emoticons. In: $20138^{\text {th }}$ ACM/IEEE International Conference on Human-Robot Interaction (HRI), Tokyo, 3-6 March, Japan

Clean \& Green Singapore, 2018. School Programmes. Available Online at https://www.cgs.sg/ programmes/school-programmes/buddy-clean-workshop, Accessed on 30 June 2018

Comber, R., Thieme, A., Rafiev, A., Taylor, N., Krämer, N., Olivier, P., 2013. BinCam: Designing for Engagement with Facebook for Behavior Change. In: Human-Computer Interaction-INTERACT 2013, Cape Town, 2-6 September, South Africa

Comber R., Thieme, A., 2017. BinCam: Evaluating Persuasion at Multiple Scales. In: Behavior Change Research and Theory: Psychological and Technological Perspectives, Little, L., Sillence, E., Joinson, A. (eds.), Academic Press, London, UK, pp. 181-194

Deterding, S., Khaled, R., Nacke, L.E., Dixon, D., 2011. Gamification: Toward a Definition. In: CHI 2011 Gamification Workshop Proceedings, Vancouver, British Columbia, 7-12 May, Canada

Diah, N.M., Ismail, M., Ahmad, S., Mahmud, M.I., 2012. Adaptation of Environmental Anticipation in Educational Computer Game. Procedia-Social and Behavioral Sciences, Volume 42, pp. 74-81

Dicheva, D., Dichev, C., Agre, G., Angelova, G., 2015. Gamification in Education: A Systematic Mapping Study. Educational Technology \& Society, Volume 18(3), pp. 75-88

Duggan, K., Shoup, K., 2013. Business Gamification for Dummies. New York, USA: Wiley

Dung, M.D., Mankilik, M., Ozoji, B.E., 2017. Assessment of College Students' Knowledge and Attitudes toward Solid Waste Management in North Central Zone of Nigeria. Science Education International, Volume 28(2), pp. 141-146

Eco, 2018. Available Online at https://eco.gamepedia.com, Accessed on 30 June 2018

EcoFun, 2018. Available Online at http://ecofun.id/about-us/, Accessed on 30 June 2018

Eder, M.S., 2016. iTrash: Proper Waste Segregation Mobile Game. Indian Journal of Science and Technology, Volume 9(42), pp. 1-8

Entertainment Software Association (ESA), 2017. Essential Facts about the Computer and Video Game Industry. Available Online at http://www.theesa.com/article/2017-essentialfacts-computer- video-game-industry/, Accessed on 30 June 2018

Entertainment Software Association (ESA), 2018. US Video Game Industry Revenue Reaches $\$ 36$ Billion in 2017. Available Online at http://www.theesa.com/article/us-video-gameindustry- revenue- reaches-36-billion-2017/, Accessed on 30 June 2018 
European Environmental Bureau, Eunomia, 2017. Recycling-Who Really Leads the World? (Issue 2). Available Online at: http://www.eunomia.co.uk/reports-tools/, Accessed on 30 June 2018

Fadhil, A., Villafiorita, A., 2017. An Adaptive Learning with Gamification \& Conversational UIs: The Rise of CiboPoliBot. In: UMAP '17 Adjunct Publication of the $25^{\text {th }}$ Conference on User Modeling, Adaptation and Personalization, Bratislava, 9-12 July, Slovakia, pp. 408-412

Felicia, P., 2014. Game-based Learning: Challenges and Opportunities. Newcastle upon Tyne, UK: Cambridge Scholars Publishing

González, C.S., Gómez, N., Navarro, V., Cairós, M., Quirce, C., Toledo, P., Marrero-Gordillo, N., 2016. Learning Healthy Lifestyles Through Active Videogames, Motor Games and the Gamification of Educational Activities. Computers in Human Behavior, Volume 55, pp. $529-551$

González-Briones, A., Valdeolmillos, D., Casado-Vara, R., Chamoso, P., Garcia Coria, J.A., Herrera-Viedma, E., Corchado, J.M., 2018. GarbMAS: Simulation of the Application of Gamification Techniques to Increase the Amount of Recycled Waste through a Multi-agent System. In: Distributed Computing and Artificial Intelligence, $15^{\text {th }}$ International Conference, Toledo, 20-22 June, Spain, pp. 332-343

Hamari, J., 2013. Transforming Homo Economicus into Homo Ludens: A Field Experiment on Gamification in a Utilitarian Peer-to-peer Trading Service. Electronic Commerce Research and Applications, Volume 12(4), pp. 236-245

Hirose, Y., Suriura, J., Shimomoto, K., 2004. Industrial Waste Management Simulation Game and Its Educational Effect. Journal of Material Cycles and Waste Management, Volume $6(1)$, pp. 58-63

Hoornweg, D.A., Bhada-Tata, P., 2012. What a Waste: A Global Review of Solid Waste Management, Urban Development Series Knowledge Papers No. 15. Available Online at http://documents.worldbank.org/curated/en/302341468126264791/What-a-waste-a-globalreview-of-solid-waste-management, Accessed on 30 June 2018

Jones, B.A., Madden, G.J., Wengreen, H.J., Aguilar, S.S., Desjardins, E.A., 2014. Gamification of Dietary Decision-Making in an Elementary-School Cafeteria. PLoS ONE, Volume 9(4), pp. $1-8$

Juan, Y.K., Chao, T.W., 2015. Game-based Learning for Green Building Education. Sustainability, Volume 7(5), pp. 5592-5608

Kapp, K.M., Blair, L., Mesch, R., 2013. The Gamification of Learning and Instruction Fieldbook: Ideas into Practice. San Francisco, CA, USA: Wiley

Kasurinen, J., Knutas, A., 2018. Publication Trends in Gamification: A Systematic Mapping Study. Computer Science Review, Volume 27, pp. 33-44

Katsaliaki, K., Mustafee, N., 2012. A Survey of Serious Games on Sustainable Development. In: Proceedings of the 2012 Winter Simulation Conference, Berlin, 9-12 December, Germany, pp. 1-13

Katsaliaki, K., Mustafee, N., 2015. Edutainment for Sustainable Development: A Survey of Games in the Field. Simulation \& Gaming, Volume 46(6), pp. 647-672

Kayımbaşığlu, D., Oktekin, B., Hacı, H., 2016. Integration of Gamification Technology in Education. Procedia Computer Science, Volume 102, pp. 668-676

Kiryakova, G., Angelova, N., Yordanova, L., 2014. Gamification in Education. In: Proceedings of $9^{\text {th }}$ International Balkan Education and Science Conference, Trakya University, Edirne, 16-18 October, Turkey 
Kostenius, C., Hallberg, J., Lindqvist, A.K., 2018. Gamification of Health Education: Schoolchildren's Participation in the Development of a Serious Game to Promote Health and Learning. Health Education, Volume 118(4), pp. 354-368

Licy, C.D., Vivek, R., Saritha, K., Anies, T.K., Josphina, C.T., 2013. Awareness, Attitude and Practice of School Students towards Household Waste Management. Journal of Environment, Volume 2(6), pp. 147-150

Liu, Y., Alexdandrova, T., Nakajima, T., 2011. Gamifying Intelligent Environments. In: Ubimui '11 Proceedings of the 2011 International ACM Workshop on Ubiquitous Meta User Interfaces, Scottsdale, New York, 1 December, USA, pp. 7-12

Lynch, S., 2018. OpenLitterMap.com-Open Data on Plastic Pollution with Blockchain Rewards (Littercoin). Open Geospatial Data, Software and Standards, Volume 3(6), pp. $1-10$

Matallaoui, A., Hanner, N., Zarnekow, R., 2017. Introduction to Gamification: Foundation and Underlying Theories. In: Gamification: Using Game Elements in Serious Contexts, Stieglitz, S., Lattemann, C., Robra-Bissantz, S., Zarnekow, R., Brockmann, T. (eds.), Springer International Publishing, Switzerland, pp. 3-18

Morganti, L., Pallavicini, F., Cadel, E., Candelieri, A., Archetti, F., Mantovani, F., 2017. Gaming for Earth: Serious Games and Gamification to Engage Consumers in Proenvironmental Behaviours for Energy Efficiency. Energy Research \& Social Science, Volume 29, pp. 95-102

Mostowfi, S., Mamaghanib, N.K., Khorramarb, M., 2016. Designing Playful Learning by using Educational Board Game for Children in the Age Range of 7-12: A Case Study: Recycling and Waste Separation Education Board Game. International Journal of Environmental \& Science Education, Volume 11(12), pp. 5453-5476

Nath, T., 2016. Investing in Video Games: This Industry Pulls in More Revenue than Movies, Music. Available Online at https://www.nasdaq.com/article/investing-in-video-games-thisindustry-pulls-in-more-revenue-than-movies-music-cm634585, Accessed on 30 June 2018

National Environment Agency, 2018. Waste Minimisation and Recycling: At Home. Available Online at https://www.nea.gov.sg/our-services/waste-management/3r-programmes-andresources/waste-minimisation-and-recycling/at-home, Accessed on 14 August 2018

Newzoo, 2017. 2017 Global Games Market Report: Trends, Insights, and Projections toward 2020. Available Online at https://newzoo.com/insights/trend-reports/newzoo-globalgames-market- report-2017-light-version/, Accessed on 30 June 2018

Pivec, M., Dziabenko, O., Schinnerl, I., 2003. Aspects of Game-based Learning. Available Online http://citeseerx.ist.psu.edu/viewdoc/download?doi=10.1.1.97.8613\&rep=rep1\&type=pdf, Accessed on 30 June 2018

Prensky, M., 2003. Digital Game-based Learning. Computers in Entertainment, Volume 1(1), pp. 21-21

Recyclebank, 2012. Gamification Revolutionizes Consumer Recycling Incentives. Business and the Environment, January 2012, pp. 10-10

Rutberg, S., Lindqvist, A., 2018. Active School Transportation is an Investment in School Health. Health Behavior and Policy Review, Volume 5(2), pp. 88-97

Seaborn, K., Fels, D.I., 2015. Gamification in Theory and Action: A Survey. International Journal of Human-Computer Studies, Volume 74, pp. 14-41

Sekito, T., Prayogo, T.B., Dote, Y., Yoshitake, T., Bagus, I., 2013. Influence of a Communitybased Waste Management System on People's Behavior and Waste Reduction. Resources, Conservation and Recycling, Volume 72, pp. 84-90 
Soboleva, E.V., Galimova, E.G., Maydangalieva, Z.A., Batchayeva, K.K.M., 2018. Didactic Value of Gamification Tools for Teaching Modeling as a Method of Learning and Cognitive Activity at School. EURASIA Journal of Mathematics, Science and Technology Education, Volume 14(6), pp. 2427-2444

Webley, S., Cham, K., 2016. Designing for the Play Instinct: Gamification, Collective Voodoo and Mumbo Jumbo. In: The Business of Gamification: A Critical Analysis, Dymek, M., Zackariasson, P. (eds.), Routledge, UK, pp. 182-207

World Bank, 2018. Brief: Solid Waste Management. Available Online at http://www.worldbank.org/en/topic/urbandevelopment/brief/solid-waste-management, Accessed on 30 June 2018

Wu, K.C., Huang, P.Y., 2015. Treatment of an Anonymous Recipient Solid-waste Management Simulation Game. Journal of Educational Computing Research, Volume 52(4), pp. $568-600$

Yang, J.C., Quadir, B., Chen, N.S., 2016. Effects of the Badge Mechanism on Self-efficacy and Learning Performance in a Game-based English Learning Environment. Journal of Educational Computing Research, Volume 54(3), pp. 371-394

Ye, E., Fang, Y., Liu, C., Chang, T.J., Dinh, H.Q., 2007. Appalachian Tycoon: An Environmental Education Game in Second Life. Second Life Education Workshop, Volume 72, pp. 72-77 